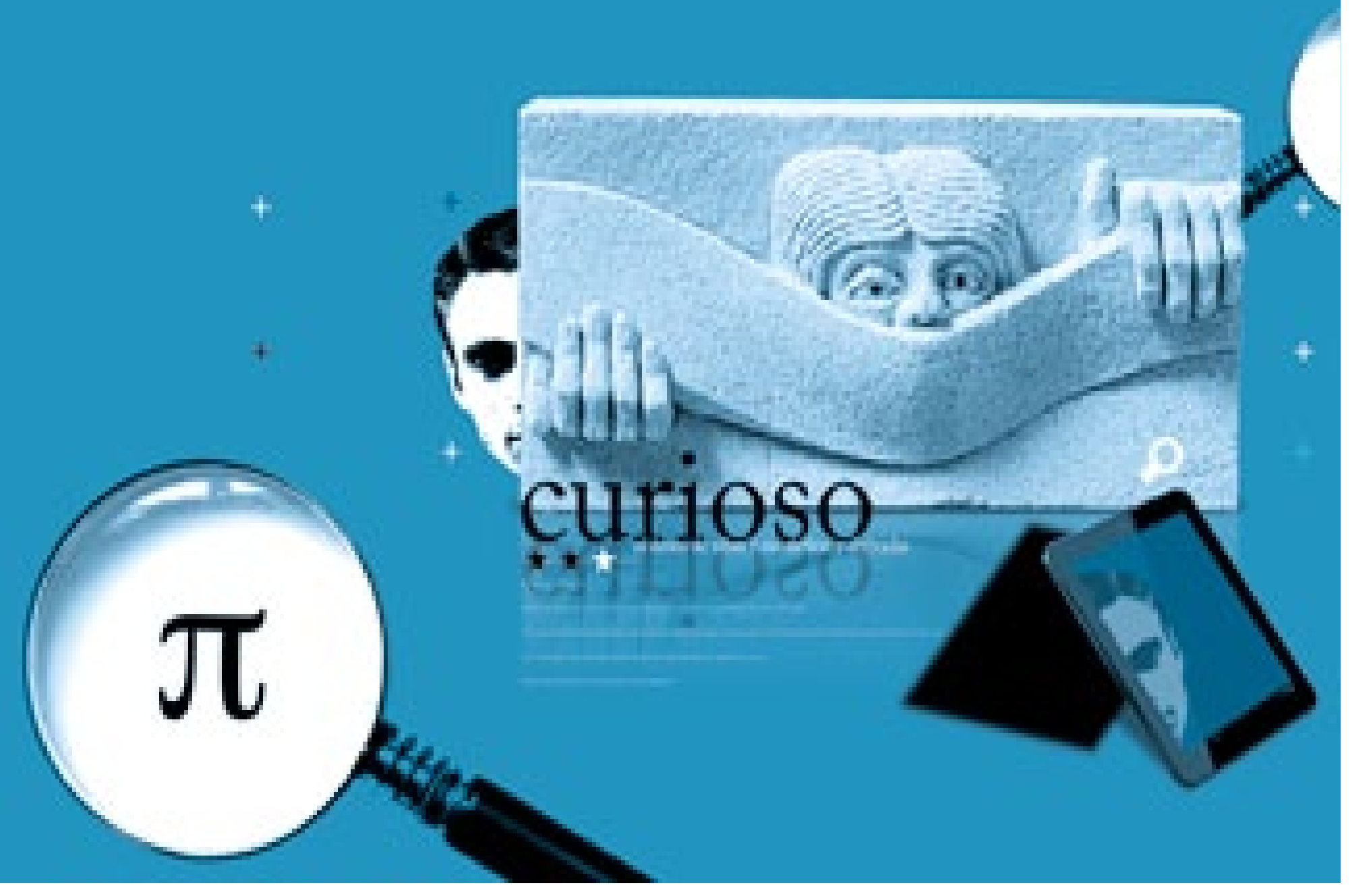

\title{
Curioseando (Saberes e ignorancias) $^{1}$
}

Este artículo fue publicado en Buenos Aires, por el Estante Editorial en su colección seminarios del CEM. 


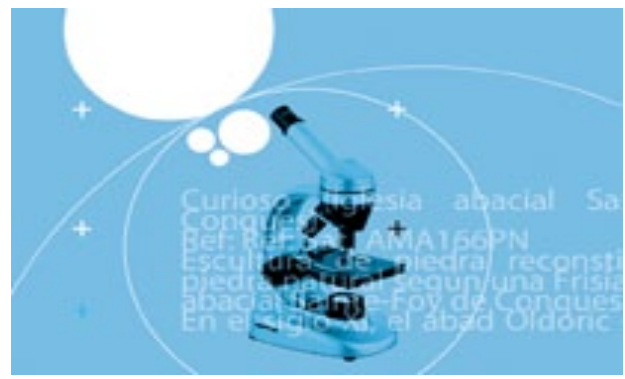

\section{Curioseando \\ (Saberes e ignorancias)}

\section{Resumen:}

El artículo busca organizar algunas ideas acerca de los saberes, la formación de educadores y el ejercicio del oficio de ser educador, que surgieron en el momento de instaurar el XIV Seminario Internacional del CEM. Para hacerlo, se plantea la relación entre curiosidad y saber inscritos como hecho inherente a lo humano, y cómo, en el sentido de lo transmisible, se incorporan al ámbito educativo en la formación de parámetros del deber conocer, lo conocido y las formas de transmisión del conocimiento; todo, dentro de una forma dinámica de interacción con el otro.

Palabras clave: Formación docente, curiosidad, conocimiento, saber, saber en el aula.
Snooping

(Knowledge and ignorance)

\section{Abstract:}

The article seeks to organize some ideas about knowledge, teacher training and the profession of being an educator, that arose at the time of organizing the International Seminar XIV CEM. To do so, it shows the relationship between curiosity and know fact registered as inherent to the human, and how, in the sense of the communicable, are incorporated into the educational field in forming parameters should know, the known and the modes of transmission knowledge, all within a dynamic form of interaction with the other.

Keywords: Teacher education, curiosity, knowledge, learn, learn in the classroom.

\section{Navegando \\ (conhecimento e ignorância)}

\section{Resumo:}

0 artigo visa a organizar algumas idéias sobre o conhecimento, a formação de educadores e praticando a ser um educador, que surgiu no momento da criação do XIV Seminário Internacional da CEM. Ao fazê-lo, a relação Entre curiosidade e saber registado como fato inerente no ser humano, e a forma como, na acepção de encefalopatias, está incorpo-

rada no domínio da educação, da formação de parâmetros do direito saber, o conhecimento e as formas de transmissão do conhecimento; todos, dentro de uma forma dinâmica de interação com o outro.

Palavras-chave: A formação de professores, a curiosidade, o conhecimento, o saber, o saber na sala de aula.

\section{Graciela Frigerio}

Doctorat en Sciences de l’ Education. Université de Paris V. Sorbonne. 1981. Diplôme

d'Etudes Approfondies en Sciences de l'Education. Option: Sociologie. Université de Paris

V. Sorbonne. 1976. Diplôme d'Etudes Approfondies, Specialité Psychologie et Sciences de

l'Education. Option Pédagogie et Psychanalyse. Université de Paris X. 1983. Profesorado

en Ciencias de la Educación. Universidad de Buenos Aires (1975). Dirige actualmente el

Doctorado en Educacion de la UNER ( Argentina). gracielafrigerio@arnet.com.ar 


\begin{abstract}
"Si hubiera que escribir la única historia significativa del pensamiento humano, habría que escribir la de sus arrepentimientos sucesivos y sus impotencias".
\end{abstract}

Albert Camus

\section{Los curiosos (a ver... el final...)}

Desde el "comienzo"2 de lo humano, muchas obras han dado forma a los saberes (a los adquiridos, a los pendientes) y a sus contrapartes, las ignorancias (las que resultan del temor de saber, del odio a saber, de lo aún no sabido, de lo sabido rechazado), que afectan a la vida psíquica y social de los sujetos. La figura que incluimos (una de las 14 de la obra), emerge de la piedra ${ }^{3}$, observa no una escena cualquiera, sino la de un juicio. Una decisión está pendiente y acusadores, defensores e imputados pueblan la escena. Los curiosos se asoman poniendo en evidencia lo que interroga: ¿Qué pasará “después”, más allá de la muerte? La pregunta remite a otra: ¿qué pasó “antes”, en los orígenes?

Posiblemente los escultores del siglo XIII que trabajaban en la abadía sólo buscaban ofrecer una representación y crear un efecto estético a una premisa religiosa, sin embargo, a fuerza de no dejarse convencer por las casualidades, el observador coincidirá en apreciar que dos detalles adquieren relevancia: los ojos, abiertos, y las manos aferrando un lugar del cual sostenerse y a la vez donde ocultarse. Darse a ver, dejarse ver, ver, dejar de ver, volverse invisible (todo parece tramitable y volverse a dar en los conocidos juegos de los niños).

\footnotetext{
La cuestión acerca del comienzo, del origen, como interrogantes siempre abiertos, es lo que ha dado a pensar, exigido comprensión y rendición de cuentas, dado forma a las ideas y a su historización, y sustentando las producciones estéticas, que no son otra cosa que modos de lectura e interpretación propias de lo humano.

3 Se trata del Tympan de Conques, una abadía situada en un pequeño pueblo francés que forma parte del llamado "Camino de Santiago". La imagen ha sido fotografiada a partir de una reproducción que realiza el Musee du Compagnonage de Tours.
}

Asomarse para ver... asomarse al saber... Pulsión escópica a la obra ${ }^{4}$, pulsión de aprehensión trabajando, tensión en la figura que no mira serenamente, sino que inquieta con sus orificios ofrecidos, a su vez, a la mirada del espectador.

\section{Lo propiamente humano y las alteraciones recíprocas}

Nos proponemos aquí organizar algunas ideas acerca de los saberes, la formación de educadores y el ejercicio del oficio de ser educador. Las ideas de este ensayo han tenido distintas reformulaciones ${ }^{5} \mathrm{y}$, llegado el momento del XIV Seminario Internacional del CEM, (que precede a su cierre, del que nos enorgullecemos tanto como de su creación), decidimos incluir en el libro estas notas, incompletas e inconclusas, para darles la oportunidad de ser discutidas.

Tal vez, como los escritos anteriores sobre el tema tenían por objetivo reflexionar acerca de lo que la formación debía brindar, la cuestión de lo que estaba "alterado" resultaba presente pero no tenía una explicitación rotunda que consideramos necesaria: los saberes "alteran la relación con los otros" y, en consecuencia, afectan "la relación con el saber y los saberes" de distinto modo. Comencemos por retomar nuestro punto de partida (uno entre tantos posibles), la cuestión del saber concierne a lo propiamente humano.

Los humanos se caracterizan por estar habitados por enigmas estructurantes que se intentan desentrañar. Un "no saber" (no aún, no totalmente, no ahora), es decir, un saber no sabido, ignorado u olvidado habita de manera excepcional en el aparato psíquico de los sujetos. Lo enigmático trata de un manojo de interrogantes sin respuestas definitivas que movilizarán preguntas alternativas y, con ellas, la ocasión de construir saberes sobre sí y sobre el mundo.

Comienzos y finales dan, como ya mencionamos, materia a los argumentos; así, el origen y la muerte, parecen proporcionar la suficiente inquietud para la búsqueda continua saberes; igualmente la sexuación

\footnotetext{
4 Nos remitimos al texto freudiano de 1905: Tres ensayos.

5 Nos referimos al trabajo que elaboramos para la reunión del CIEP en París 2008, que escribimos para que fuera compartido en Colombia a solicitud de Alberto Martínez Boom, y a la ponencia que presentamos en el Seminario Inaugural de la Maestría en Educación de la UNER en el 2009.
} 
ofrece un territorio siempre fértil para las exploraciones del sujeto. Todas las preguntas asociadas a esos interrogantes existenciales han tenido profusas tramitaciones (teóricas, religiosas, científicas, artísticas, políticas, privadas y /o públicas). Sin embargo, parecería que ninguna de las explicaciones ofrecidas propone una comprensión definitiva, lo que es a la vez inconfortable y prometedor.

El hombre estará siempre relanzado, al seguir buscando, a continuar "curioseando" lo desconocido, y allí algunos de sus rostros adquirirán la forma de lo desconocido cognoscible y, otros, seguirán ofreciendo la opacidad motora que da libido y razón para perdurar en las búsquedas. Entendemos que son las búsquedas las que ofrecen el telón de fondo a lo propiamente humano: el deseo de saber y sus derivas y derivadas.

Cada sujeto está concernido por los saberes (sobre sí, sobre el mundo, sobre los otros y sus relaciones con ellos). Cada saber (su ignorancia, su desmentida, su internalización), afecta y altera al sujeto que, por su parte, altera al mundo cuando sobre él pone sus palabras, teje sus hipótesis (profanas, paganas, científicas, pre-teóricas, teóricas, intuitivas, sensibles, creativas, transgresoras, ingenuas, elaboradas, inteligibles, tranquilizadoras, sobrecogedoras e inquietantes en múltiples e infinitas combinaciones).

La problemática del saber en tanto algo que nos afecta y altera, a la vez que alteramos con él, el mundo, se nos ha planteado en términos singulares (de los que no daremos cuenta aquí), académicos, profesionales e institucionales. En sus 15 años de existencia, el CEM ha dado cobijo en muchas ocasiones a las intranquilidades teóricas y políticas que, como equipo, nos han sobresaltado a propósito de la tramitación "educativa" de la relación con el saber ${ }^{6}$.

Reanudaremos aquí una preocupación que, perdura y se obstina, alude directamente a la problemática de la transmisión y lo intransmisible, y concierne a esas instituciones llamadas "educativas" que ocasionalmente toman nombre y forma de "escuelas" (sobre las que pesan y se imprimen tantos debates), encargadas de vérselas y sugerir, proponer, tramitaciones a una coincidencia de extranjeridades, a los enigmas subjetivos que

\footnotetext{
6 Las producciones relacionadas con los seminarios internacionales, las publicaciones co-editadas y las publicaciones del estante editorial, relatan a su modo esta inquietud que muchas veces llevó como encabezado el concepto de "educar".
}

\section{Todo saber es una alteración, una "producción", una interpretación que busca una comprensión que se acerque a lo verdadero. 99}

habitan a los sujetos y a lo que cada sociedad interpreta políticamente (con mayor o menor pertinencia, justeza y justicia) en términos de la arbitrariedad de decidir para quienes la componen, los saberes "que tendrían que saberse” en cada tiempo y geografía.

Estas decisiones, sin duda importantes, suelen ser esquivas al momento de considerar la complejidad, pueden perderse en enunciados a propósito de cuyo pragmatismo mucho podría ponerse en duda, y terminan (en nuestra hipótesis) omitiendo aquello que hace a lo que se pone en juego y se juega para el sujeto y la especie de la que forma parte, una cadena de afectaciones y alteraciones.

En un ridículo intento por organizar la explicitación que queremos poner en juego, digamos, a modo tentativo, que ésta se desplaza e intercepta en dos registros simultáneos y entrecruzados: el territorio al que llamamos mundo interno (no desprovisto de socialidad) y el que denominamos territorios sociales (nunca carentes de expresiones y rastros de los modos de subjetivar):

- Todo saber es una alteración, una “producción”, una interpretación que busca una comprensión que se acerque a lo verdadero; a su vez, todo saber altera al sujeto, proporcionándole algo que afecta su modo de ver, de entender, decodificar y hacer. Por eso mismo, los saberes son a la vez deseados y rehuidos, adoptados o renegados, incorporados o expulsados, recordados u olvidados, activos o pasivos.

- Todo saber resulta en cada sujeto, de un cruce infinito de variables, modos singulares de tramitar y modos colectivos e individuales de significar.

- En los comienzos, y siempre después, la cuestión del saber trabaja sobre enigmas inquietantes: ¿de dónde venimos?, ¿cómo nos "hacen”? El saber sobre el origen es un saber que se quiere tener, tanto como se lo teme. Podría decirse que se trata de un intento, vano pero estructurante, de recuperar un saber sobre un tiempo anterior. Un saber cuyo insuficiente "ayuda memoria”, se sostiene en un vestigio en el cuerpo, 
en ese lugar insólito que los niños suelen señalarse como si nos indicaran que no ignoran que hubo un tiempo anterior del cual se porta una huella. A modo de hipótesis, podría insinuarse que los saberes buscados tendrán como trasfondo ese saber inaccesible sobre los comienzos, y que el emblemático ombligo será cubierto para tomar nombre de ciencia o figura de conocimiento, o simplemente (si esto existiera para el sujeto) un estilo de relación con lo ignorado, lo desestimado, lo olvidado, lo renegado.

- También en el origen, y a lo largo de la vida, el saber sobre la no-vida, o sobre la muerte, o sobre el tiempo posterior, resulta tan inquietante como el anterior. Los “curiosos" testimonian de ese asomarse a lo desconocido, intento perseverante por poner nombre y certeza a lo no sabido.

- El rechazo o las dificultades para admitir y saber acerca de lo que Michel Gribinski (2009), denomina las "escenas indeseables" (lo que podríamos entender como insoportables), sobre las que se hace tan necesario como dificultoso pensar, plantea el modo en el que pueden construirse obstáculos singulares y subjetivos a la compresión política de acontecimientos socialmente traumáticos. Entre otras cosas, porque su visión coloca al sujeto en la situación de temer quedar preso (como un voyerista, o un perverso) de los peores fantasmas.

- Toda relación de saber y toda relación con el saber (veremos esto páginas más adelante) está siempre inscripta en una trama en la que está siempre presente el más de uno.

Cabe mencionar las alteraciones que produce tanto el "no querer saber", como el no soportar que otro sepa. El trasfondo, el telón de fondo o las bambalinas, remiten siempre a escenas menos "decibles", más oscuras, menos precisas. Todo saber intenta venir a decir algo sobre aquello que como saber se nos escapará permanentemente: el saber sobre el origen, el saber sobre la sexuación, el saber sobre la muerte. Por supuesto, conciencias e inconscientes alterados abundan y producen efectos insospechados, no programables, pero no por ello menos explorables como hipótesis.

No profundizaremos aquí todas las "alteraciones" mencionadas, nos contentaremos con abrir algunas consideraciones sobre las que conciernen al "estar siendo" educador, al "estar haciendo" gestos y actos educativos sistemáticos, al amparo del nombre, de un oficio o una profesión en organizaciones concretas.

\section{El saber y el educar}

Saber es un verbo asociado a la actividad de educar. Cotidianamente se conjuga en todos los tiempos, modos y personas en los territorios escolares de todas las geografías. Se trata de un verbo acerca de cuyos sentidos no indagamos regularmente, pero que constituye y deviene en prescripción curricular, contenidos, prácticas, experiencias, efectos. El sustantivo suele ser traducido en contenidos. Imposible sortear el verbo y el sustantivo al tiempo de reflexionar sobre sus alteraciones en los territorios educativos.

Problemática, esta última, que en materia de formación de los educadores dispone de una suerte de repertorio acotado ${ }^{7}$ cuyas principales variaciones ${ }^{8}$ han sido impuestas por las tendencias propias a los tiempos. A modo de ejemplos recientes pueden mencionarse las llamadas políticas de los noventas, que han ido sacando de la escena los elementos llamados de “cultura" o "formación general”, en beneficio de aspectos instrumentales; el viraje hacia aquellos enfoques "políticamente correctos" (la atención a los denominados "contextos", en particular los considerados "en riesgo", "los pobres”); las derivadas de la actualización de las corrientes dentro del mismo guión"; las "nuevas infancias y adolescencias”; el desplazamiento de las organizaciones encargadas de la formación inicial de los educadores (la tendencia a instalarlas en ámbitos universitarios).

Las modificaciones mencionadas parecen no haber impedido la reproducción de los conflictos entre disciplinas, o conjuntos de ellas, que se proponen disputar la hegemonía de la formación, ni modificado sustancialmente debates nunca saldados que expresan tensiones que no parecen hallar solución: formación general (pedagógica) / formación especializada (disciplinar); didáctica general / didácticas específicas; teoría / práctica; saber práctico, tácito, esquemas de acción/ saber

\footnotetext{
Por supuesto nos referimos a la situación planteada en nuestro país, la Argentina. Queda a criterio del lector considerar la pertinencia de este repertorio en sus propios contextos específicos de acción.

8 En este sentido, nos remitimos a Diker y Terigi (2006), en un documento de trabajo que elaboraron para el Ministerio de Educación de Argentina, titulado: "Hacia la institucionalidad del sistema formador". OEI/ IIPE/ INFOD. La versión que, sobre la base del anterior elaborara el Ministerio, puede leerse en www.me.gov.ar también puede consultarse el artículo de Birgin (2006): "Pensar la formación de los docentes en nuestro tiempo", en Terigi, F. (Comp.). Diez miradas sobre la escuela primaria. Fundación OSD y Siglo XXI Editores, Argentina.
} 
66 Se trata aquí de los saberes que solemos desatender o que preferimos conserven el lugar discreto de lo "no sabido".

proposicional, declarativo, teórico; por mencionar algunos polos de lo que se discute ${ }^{9}$, a los que se agrega el debate nunca resuelto acerca de las condiciones laborales y la carrera docente.

Pero lo más importante es que el repertorio de variaciones tampoco parece haber dado "pruebas" de su eficacia en la enseñanza y los aprendizajes, a juzgar por los resultados de las (por cierto dudosas) pruebas de resultados a las que se somete a los alumnos (y en algunos contextos a los educadores) en las tristemente famosas evaluaciones o mediciones.

La formación de los educadores ha estado y sigue estando en el centro del candelero (o en el banquillo de los acusados). Políticas curriculares, reformas estructurales, reubicación de la formación de grado de los educadores, nexos con instituciones universitarias; insistencia en volver reglamentario para las instituciones de formación el tríptico: formación-investigación-extensión; énfasis e inversión desmedida en el despliegue de toda suerte de mediciones (llámense evaluaciones) ${ }^{10}$ institucionales y de los sujetos; todo ello ha coincidido o se ha sucedido sin lograr resolver de manera satisfactoria la problemática de cómo hacer funcionar un sistema educativo justo.

Significando lo anterior, un sistema que no produzca y reproduzca, bajo distintos nombres, las huellas dolorosas del fracaso escolar. Acerca del cual, la formación docente carga con una responsabilidad adjudicada política, social y pedagógicamente, y también con el universo de representaciones elaboradas por los

\footnotetext{
9 Véase al respecto una organización detallada y crítica de esos debates en Diker, G., y Terigi, F (1997). La formación de maestros y profesores: hoja de ruta. Paidós.

${ }^{10}$ Para explorar los matices entre evaluación, impacto, efectos, recomendamos el libro dirigido por Baudelot, Ch., y Leclercq, F (2008). Los efectos de la educación. En otro registro, para analizar lo que de todo trabajo no se deja evaluar, invitamos a la lectura del artículo de Dejours, Ch. (2006). "Evaluation et institution en psychanalyse", en la Revue Française de Psychanalyse, Oct. 2006, Tomo LXX. Puf. Puede consultarse además, entre otros textos, la revista Lo que queda de la escuela. Cuadernos de Pedagogía de Rosario 2003.
}

propios educadores acerca de lo que consideran "no pueden saber", dado que "no les ha sido enseñado" o "para lo que no fueron preparados" durante su formación, omisiones o faltas a las que atribuyen una culpa que tal vez opere como protección ante cualquier asignación de responsabilidad en la producción de dicho "fracaso".

¿Será entonces que habrá que recurrir a otros saberes? ${ }^{11}$, ¿se agotaría allí el problema? Alcanzaría con plantearse y responder una vez más, dentro del mismo cerco cognitivo, la misma pregunta: ¿Qué debe saber un educador? Pregunta que inmediatamente aparece espejando otra: ¿Qué debe saber un niño, un adolescente, un adulto, un alumno, un estudiante? Parecería que a menos que se rompiera ese espejo, y el cerco cognitivo que lo delimita, volver a preguntar lo mismo no conduciría a respuestas auténticamente novedosas.

¿Cómo se rompe el espejo?, ¿si lo intentáramos modificando, por ejemplo, algunas de las preguntas para indagar acerca de aquello que debe ser des-aprendido en el sentido de des-naturalizado?, ¿si las variaciones a introducir giraran acerca de cambios acerca de lo que se ignora y de lo que se debería desaprender para poder ignorar y dar acceso al saber?

Para evitar cualquier malentendido, aclaremos que no estamos diciendo que no hay que atender las cuestiones relativas a los contenidos de la formación, ni a los necesarios soportes de la transmisión, pero tenemos el convencimiento de que el espejo sólo se romperá si se hacen otras preguntas ${ }^{12}$, las que no se agotan en la cuestión de los contenidos ${ }^{13}$, por lo que importa hacer

\footnotetext{
${ }^{1}$ Por ejemplo, los que siendo considerados tradicionalmente adjudicados a la "formación general" fueron, en las versiones más "técnicas" de la formación, suprimidos en nombre de una concepción utilitarista del conocimiento, ¿alcanzaría con introducirlos o re-introducirlos en la formación? Sin duda estamos tentados a responder afirmativamente, a condición de que esa re-introducción se lleve a cabo con una perspectiva que los considere como parte de la tarea misma de educar. Dicho de otro modo, es imprescindible dejar de considerar a algunas disciplinas (la filosofía, la historia) como "marco", un entorno que no se vincularía con la práctica, para pasar a considerarlas como la vía privilegiada para producir un cambio de percepción sobre los efectos de la propia tarea. $\mathrm{Al}$ respecto, sugerimos revisitar los trabajos de Gabriela Diker.

${ }^{12}$ Como las planteadas por Grossi, E. P. (2006), en Qual é a chave? Todos podem aprender.

${ }^{13}$ Por ejemplo, preguntarse si la clave no se halla en la afirmación de Joseph Jacotot cuando sostiene que, si la educación tiene un potencial emancipatorio, el mismo no reside en los contenidos sino en la relación. Obviamente el lector comprenderá que la propuesta de Jacotot no pue-
} 
referencia aquí a algunas de las posibles alteraciones a considerar ${ }^{14}$. En educación nos encontramos con:

- La “alteración de los saberes” que se presentan bajo la forma de pre-juicios. Decimos que un prejuicio es "un saber alterado" en el sentido de falseado. Se trata de "supuestos saberes" que se atribuyen certeza y, con desparpajo, se ofrecen orondos al tiempo que se pasean por algunas instituciones educativas donde se sienten "en casa", dado que se hallan confortablemente instalados en no pocas representaciones. Los prejuicios son "supuestos saberes" que se han naturalizado, instrumentales, escapan y sortean muy a menudo exitosamente cualquier crítica. Refractarios al análisis, podría decirse de ellos que operan sobre la base de saberes "abusados" y resultan "abusadores” de los sujetos sobre los que se aplican.

- "Los saberes que se alteran" - por la esterilización que sobre ellos se ejerce, o los baños de neutralización que se llevan a cabo (ver al respecto en este mismo libro el artículo de Baudelot), de modo tal que por “omisión” a menudo no suelen formar parte de la definición y construcción de políticas.

- "Los saberes que nos alteran como educadores": se trata aquí de los saberes que solemos desatender o que preferimos conserven el lugar discreto de lo "no sabido”, y que se ponen en juego sin avisarnos ni advertirnos cada vez que un encuentro se produce, dando lugar a una experiencia o a su renegamiento. Es tal su potencial movilizador, que suelen ser "desatendidos", "no sabidos". A modo de ejemplo mencionemos el saber sobre nuestro propio mundo interno; sobre las razones y sin razones por las que ejercemos el oficio. Podemos decir que se trata de los saberes que resultan de las trampas que el inconsciente nos depara, cuando queremos sortearlo y optamos por economizar la elaboración de nuestra propia relación con lo desconocido.

- "Los saberes alterados por la conciencia”, que expresan lo que se altera por nuestro trabajo de tramitación de la relación con el mundo, lo conocido y lo a por conocer.

de confundirse ni traducirse en términos que han estado tan en boga, como "contenidos procedimentales" o "actitudinales". Nada más lejos del pensamiento del profesor Jacotot, quien se refería a un manojo de principios filosóficos relacionados con la "igualdad de las inteligencias".

${ }^{14}$ Dejaremos de lado exprofeso la tramitación /alteración conocida como "transposición didáctica", acerca de la cual muchos han hecho investigaciones y puesto en evidencia la producción de "falsos" saberes.
- "Los saberes alterados por las elaboraciones inconscientes" (o por la imposibilidad de elaboración), aludimos a lo que se mueve y conmueve en el mundo interno del sujeto, en su encuentro con los dispositivos y los otros.

- "Los saberes que alteran la relación pedagógica", resultantes de la intensa actividad hermenéutica (que todo el tiempo transita del inconsciente a la conciencia en un permanente va y viene), a la que se libran los destinatarios de nuestra transmisión, vinculados a las respuestas que se formulan acerca de las eventuales e hipotéticas o reales razones por las cuales finalmente "estamos ahí".

Páginas más adelante retomaremos la exploración de algunas de las formas alteradas (o a alterar) mencionadas, pero antes recordemos que "curiosear" estas temáticas requiere el pensar "entre disciplinas" 15 , que indica que toda "relación de saber" (como podría decirse de la relación "de" objeto en psicoanálisis), se da sobre el telón de fondo de "la relación de desconocido", sobre la que trabajara G. Rosolato ${ }^{16}$ y, a la vez se inscribe en lo que llamamos el carácter estructurante de la extranjería o, como hemos afirmado en trabajos

15 Para abordar la cuestión de la relación con potencial emancipatorio se requieren los aportes de un pensar "entre disciplinas”, como diría Rancière (2007). "Pensar entre las disciplinas". En Frigerio, G., y Diker, G. (Comp.). Educar: (sobre) impresiones estéticas. Del estante editorial, Buenos Aires. En este caso, quizás se trate del borde en cuyos intersticios dialogan y se exploran la filosofía y el psicoanálisis. Si la filosofía política da a ver (da a saber) sobre la igualdad, la confianza, la responsabilidad; el psicoanálisis, aporta un interesante puñado de conceptos al explorar el territorio pedagógico.

Recordaremos' en desorden, algunos de los conceptos a los que aludimos: identificación, transferencia, amor de transferencia, objeto transicional, apuntalamiento, holding, elaboración, sublimación. La misteriosa pulsión epistemofílica a la que aludía Freud y la oferta y tramitación sublimatoria (nos remitimos a Frigerio, G. (2005). "En la cinta de Moebius”, En Educar: ese acto político. Del estante editorial, Buenos Aires; han sido maneras de nombrar a la vez algo tan propio al aparato psíquico individual, como aquello que hace al trabajo colectivo que es propio de la identidad de la cultura (Algunos de estos aspectos están señalados, en otros términos en el libro Vargas Guillen y otros (2007). Formación y subjetividad, de la Universidad Pedagógica Nacional, Bogotá. Otros pueden hallarse en la misma obra freudiana. La revista Europe, le da dedicado el número de octubre de 2008 a Freud et la cultura.

${ }^{16}$ En La relation d'inconnu. Gallimard, Paris, 1978. (Traducido al español en 1981). 
anteriores, el principio que sostiene que no hay conocimiento sin extranjeridad.

\section{Demos más precisión a algunas nociones:}

La "relación al saber" (o con el saber), de la cual se ocupa y acerca de la cual reflexiona la pedagogía, es la trama que se establece sobre el fondo de la relación de saber, requiere admitir que no se trata sólo, no exclusivamente, de una vinculación con un objeto de conocimiento nuevo. Lo que se juega (llámelo el lector: conflicto socio-cognitivo; ruptura epistemológica) es, en la interlocución con el pensamiento de un otro significado, una relación transferencial. En cuyo marco se reconfigura la relación del sujeto consigo mismo (y en particular con sus posibilidades de conocer y aprender), con los otros, con el tiempo, el lenguaje, y los saberes y conocimientos entendidos como lenguas extranjeras $^{17}$ (es decir territorios culturales, productos históricos, desconocidos y cognoscibles, con sus propios códigos y signos, con nuevas palabras, otros sentidos y diferentes gramáticas).

Beillerot (1989), considera a la relación al saber, como "un proceso por el cual un sujeto (consciente e inconsciente) a partir de saberes adquiridos, produce nuevos saberes singulares que le permiten pensar, transformar y sentir el mundo natural y social". Para Charlot (1997), esa relación involucra:

"El conjunto de relaciones que un sujeto establece con un objeto, un contenido de pensamiento, una actividad, una relación interpersonal, un lugar, una persona, una situación, una ocasión, una obligación, etc., ligadas de algún modo, al aprendizaje y al saber; es también relación con el lenguaje, con el tiempo, con la actividad en el mundo y sobre el mundo, con los otros y consigo mismo, como sujeto más o menos capaz de aprender tal cosa, en tal situación”.

Las modalidades de relación al saber (a los saberes) están condicionadas por lo que se ofrece en la situación y en relación. En términos objetivos lo significado epocalmente, la presentación del objeto $^{18}$, la disponibilidad para volverlo accesible, los dispositivos instituidos, el estilo de presencia del referente. En términos subjetivos, lo que está en juego son soportes identifica-

\footnotetext{
${ }^{17}$ Sugerimos la lectura de Alexakis, V. (2005). Las palabras extranjeras. Buenos Aires: Estante editorial.

${ }^{18}$ Si bien el uso de la noción "objeto” podría cuestionarse, dejamos provisionalmente este término hasta poder definir mejor aquello de lo que se trata, entendiéndolo como Donald Winnicott.
}

torios con modelos transferenciales de relación con el conocimiento, el sentido del saber en el funcionamiento del aparato psíquico; representaciones acerca de lo que se capaz de aprender, de lo que el otro es capaz de aprender, acerca del tiempo, etc.

Algunas investigaciones ${ }^{19}$ han podido poner en evidencia que la relación de saber se modifica cuando se ponen a disposición objetos culturales de alta valoración social, o de alta valoración subjetiva y singular. Ambas contribuyen a que el objeto se signifique también para aquel a quien le ha sido ofrecido. En este sentido, se ha puesto en evidencia que lo que se da a saber es más y otra cosa que un contenido, lo que se da a ver y a saborear (de eso trata dar a saber) es que los adultos tienen confianza en la capacidad de pensar y aprender de aquel con quien se desea compartir lo que hay, lo que se sabe y lo que se ignora y deberá ser buscado, descubierto, hallado.

Dicho de otro modo, educar no sólo no coincide con responder a una demanda, sino que está lejos de ser simplemente una "mostración". Tampoco se trata solamente de sostener una oferta, sino de que esta se halle imbuida de un sentido valioso para el que hace que se ocupa de volverla disponible (de esto trataría su oficio). Es esta carga simbólica la que produce un efecto, una eficacia simbólica apuntalada por -apuntalada enrelaciones transferenciales.

Sobre estas cuestiones, algunos colegas están formulando hipótesis inquietantes, así afirman que lo hoy estaría en crisis son las razones para aprender, para Blais, Gauchet y Ottavi (2008), la explicación de la crisis se halla en una "deslegitimación de la anticipación" ${ }^{20}$, y en un cambio en la relación con la tradición.

La legitimidad de la anticipación, el sentido que sostiene la acción y acerca del cual se promete que será descubierto après coup (es decir a la vez en diferido

\footnotetext{
${ }^{19}$ Remitimos a los trabajos del CEM y el llamado proyecto DAS, acerca del cual puede leerse en la página Web del CEM Fundación: Frigerio, G., y Diker, G. (Comp.) (2005). Acerca del saber, de la relación de saber y de las condiciones para el aprender. Informe de investigación elaborado para la UNESCO /OREALC. Buenos Aires, y en el trabajo que Diker (2006), publicara en Las formas de lo escolar.

${ }^{20}$ Toda actividad de enseñanza, todo acto de transmisión supone un adulto capaz de anticiparse a un tiempo futuro del pequeño, ofrecer un sentido que el más chico sólo podrá comprobar más adelante. Es la legitimidad de la posición del adulto lo que da sentido a que insista en ofrecer sentidos en los que un pequeño debe confiar sin poder constatar.
} 
-más tarde- más adelante y a la vez es algo que se le atribuye a posteriori a algo que ya ha ocurrido, creando así un sentido que resulta de la interpretación tardía de lo ya acontecido), es un requisito de todo gesto pedagógico. Sabemos que tradición es una interlocución que hace tanto a la cultura -es desde la tradición que se desplegaron y despliegan los gestos para los desconocidos del futuro aún por llegar ${ }^{21}$ - , como a un componente de las políticas de la memoria y de la justicia (como las entendía Derrida) ${ }^{22}$. Por supuesto, los argumentos que sostienen son interesantes y ameritan ser ampliados o reformulados.

Podría argumentarse que lo que ocurre está, al menos parcialmente, vinculado a la confusión que resulta de remodelaciones identitarias que han desdibujado la asimetría inter-generacional. La diferencia inter-generacional (que no debe ser sinónimo de desigualdad inter-generacional), parece ser un componente importante en la transmisión entre grandes y pequeños, su dilución no podría sino contribuir a la crisis de las relaciones de saber.

Podría agregarse que lo que hace a esta crisis es el entrecruzamiento de dos cuestionamientos: el que pesa sobre las razones del enseñar y la que lastra las razones del aprender. A esta combinación han aportado la mercantilización del conocimiento, la hipervalorización de sus características pragmáticas, el utilitarismo, la pretensión del pensamiento único (para E. Enriquez estas serían expresiones de una pulsión de muerte des-enlazada) ${ }^{23}$ y el despojo que, en manos de los tecnócratas, concreta un desdibujamiento de los significados de ciertos campos del saber y de sus construcciones.

Los autores de referencia, sugieren que quizás nos encontremos, para la llamada sociedad del conocimiento, en una situación paradojal, dicen Blais, et al (2008): "de una bella ironía de la historia, por la cual la sociedad del conocimiento podría volverse aquella en la que el deseo de saber no tendría lugar” (p. 67). La hipótesis toma para ellos forma de pregunta: “¿estaremos asistiendo a la emergencia de una sociedad post-adámica?” (p. 68). Aludiendo así a un abandono del rasgo

\footnotetext{
${ }^{21}$ Remitimos a los trabajos del psicoanalista Laplanche.

${ }^{22}$ En Los espectros de Marx.

${ }^{23} \mathrm{Al}$ respecto recomendamos la lectura del número de Octubre de 2006, de la Psychanalyse et institutions. (2006). T. LXX.
}

\section{La diferencia intergeneracional (que no debe ser sinónimo de desigualdad inter-generacional), parece ser un componente importante en la transmisión
entre grandes y pequeños. 99}

de identidad míticamente atribuido a los hombres en los tiempos fundacionales del relato bíblico.

Quizás valdría la pena mencionar que, desde nuestra perspectiva, la problemática actual podría (o debería) interpretarse menos como una supuesta extinción de la pulsión epistemofílica, y más como el resultado de las políticas des-subjetivantes ${ }^{24}$ que han generado un déficit de re-conocimiento. Si, como afirma Paul Ricoeur (2004), es el reconocer lo que abre camino al conocer, hay que admitir que nos enfrentamos a un problema político que no podrá saldarse exclusivamente con ninguna política educativa que haga toda su apuesta en un diseño curricular, o una formación en las disciplinas o en las didácticas.

¿Estamos dispuestos a formular otras preguntas para el territorio y sobre los territorios de la formación? Si lo que emancipa no fuera el contenido (como lo sugieren Jacotot y Rancière), sino la relación entre maestro y alumno: ¿es posible formar a nuevos educadores en un estilo de relación que propicie la emancipación ${ }^{25}$, es decir que se plantee como ocasión/oportunidad de desafiar a las profecías de fracaso, lo que requiere ignorar el saber que ofrecen los pre-juicios?

Si los contenidos, aún sin ser en sí mismos emancipatorios, son los que, triangulando las relaciones pedagógicas, justifican modos de institucionalización: ¿es posible formar en una relación a los contenidos que sostenga una correspondencia pedagógica institucionalizada y significativa capaz de ofertar saberes e insista en necesarios des-aprendizajes?

Si lo que estuviera en juego fuera a la vez, la textura de un sistema relacional de al menos tres términos: la relación inter-subjetiva basada en los principios de la igualdad y la confianza que se tramita como amor

\footnotetext{
${ }^{24}$ La noción tiene larga data, nos remitimos a viejos trabajos de Marcuse y a la obra de Zizek, entre otros.

${ }_{25}$ Para analizar el concepto de emancipación, sugerimos el trabajo publicado Sous la direction de Navet, G (2002). L'emancipation.
} 
de transferencia; la relación intra-subjetiva del sujeto con el objeto de conocimiento; asociada a las relaciones sociales que asignan una significación social cuyo sentido constituye un valor agregado de sentido a la experiencia educativa institucionalizada, ¿sería posible propiciar políticas de formación, que sostuvieran una oferta simbólica que a su vez fuera superficie de apuntalamiento a lo que se tramita inter e intra, subjetivamente?

Una de las tantas cadenas asociativas posibles (no la única) frente a una parte de lo expuesto, podría expresarse en los siguientes términos: cada sujeto, desde las lógicas de su aparato psíquico, sostiene con el saber relaciones que tienen como sustrato una relación de saber; la misma, hace holding (apoyo) a las relaciones con el saber (relación al saber). Esa relación al saber se encuentra propiciada, facilitada, alentada, cuando la anticipación que es propia a todo gesto pedagógico, cuenta con un alto grado de legitimación (social, cultural). La relación al saber se halla sumamente dificultada, si no imposibilitada, cuando no está acompañada y precedida por un reconocimiento (por políticas de reconocimiento), dado que éste establece una suerte de secuencia con el conocer. Dicho de otro modo, es el reconocimiento el que abre la puerta al conocer.

\section{Los saberes "propios" del educar}

No sin humor ni ironía, destacaremos, sin pretender agotarlos todos, la multiplicidad de saberes que estamos acostumbrados a considerar como agentes en juego para el acto de educar. Por supuesto, hay distintas maneras de nombrarlos, las más tradicionales, aquellas que expresan la intención instituyente de nuevos paradigmas, las que aluden a aspectos metodológicos, las que remiten a los destinatarios nombrados en tanto grupo etario o por su oficios; las que se han considerado prioritarias, complementarias, decorativas, significativas, útiles, innecesarias, superfluas, básicas, aplicadas...

Los territorios concretos y las investigaciones nos señalan saberes adjetivados de otro modo: saberes insuficientes, saberes disciplinarios demasiado disciplinados (demasiado didactizados); saberes renegados (aquellos sobre los cuales se prefiere no saber); temidos (aquellos que se elige no tomar en cuenta); frágiles (los saberes rebeldes, conmovedores, preocupantes, censurados); los saberes a no desconocer (las lecciones de lo ya sabido, no siempre atendidas); los saberes a interrogar (aquellos que brillan en el firmamento del pensamiento hegemónico de sucesivas actualidades y actualizaciones); saberes estallados (aquellos arquetipos que parecen ya no decir nada a nadie); saberes desestimados (el saber del adulto sobre sí mismo y sobre su elección de profesión); saberes pendientes de comunicación, cuya construcción y socialización se halla limitada (la producción de los propios maestros/ pedagogos), límite, este último, instalado por lo que E. Enriquez (2006), señala como rasgo de estos tiempos: la ambigüedad entre el deseo y el miedo a pensar, como por los cercos cognitivos hegemónicos que tienden a un más de lo mismo renombrado, rehusándose a aprender las lecciones de lo ya hecho cuyos efectos son ya sabidos.

Podría decirse también que hay saberes a compartir (la oferta cultural que debe volverse disponible para todos); saberes felizmente incompletos; saberes tenebrosos y obstaculizantes, es decir aquellos saberes que ofician de pantalla impidiendo el encuentro con el otro; saberes a ignorar, porque son ocultadores y por ello mismo operan al modo de "saberes obturantes"; saberes ignorados (saberes no sabidos o desestimados); saberes a ignorar (o des-aprender), entendiendo por tales a aquellos que impiden las relaciones emancipatorias; saberes a construir; saberes "que cuentan", saberes que no entran en ninguna cuenta o no deben ser contabilizados; todos ellos conciernen, forman parte de la educación e integran una suerte de repertorio que afecta y altera las maneras de comprender la formación de los educadores. A veces se inscriben e institucionalizan siguiendo protocolos formales y prescripciones curriculares, en otras ocasiones, circulan de manera informal, andan por los pasillos de las instituciones, no se exploran en bibliografías, se comentan como secretos o se silencian.

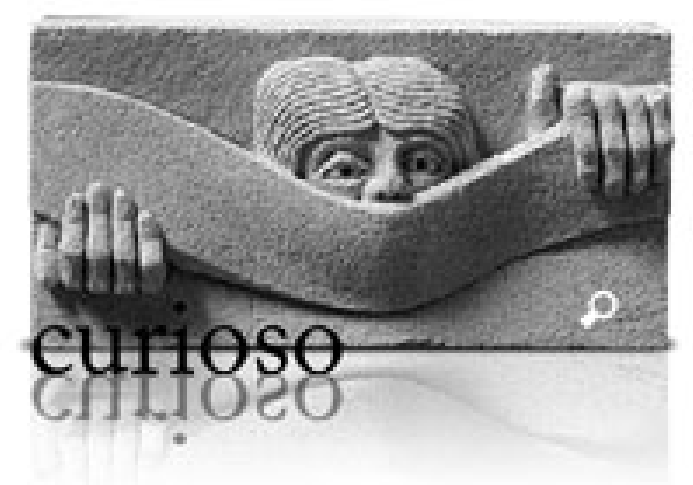


Queremos referirnos aquí a algunos de ellos (cada lector podrá completar la incompleta enumeración y el insuficiente tratamiento), darles una momentánea centralidad ateniéndonos al origen etimológico de la palabra centrum, que remite menos a un punto geométrico que a un aguijón o a un reacomodamiento de piezas. Lo haremos siguiendo asociaciones alrededor de una idea central, trabajada por Frigerio, G y Diker, G. (2004): abordar la formación de los educadores es pensar la problemática de la transmisión y reflexionar acerca de saberes a aprehender y aprender ${ }^{26}$, como a propósito de aquellos que deben ser des-aprendidos para ser ignorados:

- Un saber acerca de lo que se trata (lo que escapa a toda definición técnica, instrumental o de pretendida neutralidad).

- El curioso saber necesario: el saber ignorar.

- El saber que no se debería ignorar: el saber sobre sí.

- Un cierto saber sobre lo que cuenta (sin ninguna certeza confortable) y no es del orden de un régimen contable.

\section{Un saber acerca de lo que se trata (lo que escapa a toda definición técnica, instrumental o de pretendida neutralidad)}

Ejercer una profesión implica, desde nuestra perspectiva, una suerte de "saber" sobre ella, una manera de entenderla. ¿De qué trata la educación?, ¿de qué se trata en educación?, ¿en qué consiste educar?, ¿qué sentidos "trabajan" en el ejercicio de la educación? En trabajos anteriores hemos puesto a discusión conceptualizaciones que sintetizamos y transcribimos, dado que expresan nuestra perspectiva y punto de partida:

"Educar es el verbo que da cuenta de la acción jurídica de inscribir al sujeto (filiación simbólica) y de la acción política de volver disponibles las herencias, designando al colectivo como heredero. Acción política de designación que se asegura de brindar a todos la habilitación al ingreso, la interpretación y la ampliación del arkhé común, reparto hecho al modo de un don $^{27}$ que no

\footnotetext{
${ }^{26}$ No desconocemos ni desvalorizamos los "saberes objetivables de las disciplinas", pero no es sobre ellos acerca de lo que tanto se ha pensado, dicho, escrito y discutido que queremos profundizar aquí.

${ }^{27}$ Sugerimos la lectura del libro de Fustier, P. (2000). Le lien d'accompagnement. Entre don et contrat salarial. Francia: Dunod.
}

instala deuda. Esta modalidad del don ${ }^{28}$, podría decirse así: educar es dar el tiempo ${ }^{29}$, entendiéndolo como una fuerza de permisión, de autorización ${ }^{30}$ (Ricoeur, 1979) que, a su vez da lugar al Kairos, oportunidad que hace posible para todo sujeto, que su origen no devenga una condena. Las acciones mencionadas conllevan una exigencia de trabajo psíquico, dado que tanto en los términos del mundo interno, como en los de estar en el mundo común, ser parte, formar parte, tener parte, implica el acto político de ofrecer a la pulsión un destino que no sea ni la inhibición, ni el síntoma, ni la angustia. Educar es entonces, como diría Frigerio (2008), sinónimo de sostener una oferta sublimatoria”.

En otras palabras, ejercer la docencia, estar-siendo un educador, sería como lo hemos señalado en otras oportunidades, además de un oficio o profesión, una manera de entender y de llevar el oficio de vivir. Educar es estar interesado por formar parte de tramas complejas, relaciones con el mundo y con los saberes acerca de él (los ya disponibles y los a hallar); con otros sujetos, llevar adelante un trabajo y tener conciencia de que no se trata de cualquier trabajo, que algo se juega para el otro, para la sociedad posible y para el mundo deseable, que excede a toda definición curricular, no cabe exactamente en ningún contenido y no se deja apresar completamente en ninguna metodología (definiciones curriculares y metodológicas son, por otra parte, aspectos importantes pero de algún modo insuficientes).

Es desde esta perspectiva que puede comprenderse que para algunos sujetos, nada es más interesante y apasionante que ser educador ${ }^{31}$. Así, ¿qué significa ser educador?: asumir un trabajo político que exige un trabajo psíquico.

¿Trabajo político? ¿Podría llamarse de otro modo el empeño en desbaratar tantas profecías de fracaso destinadas a los sectores populares?, ¿cómo podría entenderse el sostener cotidianamente la puesta a disposición

${ }^{28}$ Nos apoyamos en la concepción del don que enuncia Derrida y no en las que explicitó M. Mauss.

${ }^{29}$ Ver al respecto, Molina, J. M. (2005). “Tiempo, don y relación educativa”. En Skliar, C., y Frigerio, G. (Comp.). Huellas de Derrida: Ensayos pedagógicos no solicitados.

${ }^{30}$ Ricoeur (1979, p. 13), distingue, en Les cultures et le temps, el tiempo que se presenta como "fuerza de permisión", de aquel que actúa como "fuerza que impide" o retiene.

${ }^{31}$ En término de Frigerio, G. (2009), en Razones para un homenaje, un documento elaborado para la Editorial Estrada que se encuentra en prensa. 
para cada nueva generación de una herencia plural y dispersa destinada al colectivo?, ¿sería posible conceptualizar de otra manera la perseverancia en ofrecer a todos elementos para comprender y modificar el mundo? Educar es "hacer política". Hacer política debe comprenderse aquí de manera curiosa: un educador es aquel que debe ignorar (no en el sentido de desconocer, sino en el sentido de que eso no determine sus acciones, sus miradas, sus intervenciones) un particular saber, el que se expresa con la tristemente famosa expresión "ya se sabe", dedicada a explicitar tomas de posición que condensan pre-juicios y proporcionan faltas excusas: "ya se sabe, nació aquí o allá"; "ya se sabe, vive en..."; "ya se sabe, sus parientes..."; "ya se sabe....". Esos saberes son "saberes obturantes" que se interponen entre cada educador y cada niño real, ocultándolo, y terminan trabajando en favor del cumplimiento de las profecías de fracaso.

Por supuesto, lo dicho no debe mal interpretarse. ¡NO! Definitivamente no da lo mismo nacer de este o de aquel lado de la calle, en la ciudad o en el poblado; disponer de calzado o andar con los pies desnudos, tener abrigo o tiritar de frio en los inviernos, tener espacios confortables y alimentos nutritivos, que penar por ellos. Lo que decimos es que aún así, cada niño tiene que tener la oportunidad de que su futuro no esté completa y exclusivamente determinado por su origen. Un educador, entonces, será aquel que se porta garante de que ningún origen devenga en una condena. Todo niño tiene derecho a no estar encarcelado en ninguna profecía.

¿Trabajo psíquico? ¿Cómo llamar de otro modo a la exigencia de pensar, al trabajo imprescindible de metacognición sobre los propios haceres, llevar la asimetría inter- generacional, elaborar el propio núcleo vivo de lo infantil en nuestro aparato psíquico de adulto, que no cesa de conmoverse ante cada otro para que no sean nuestras representaciones, pre-juicios y fantasmas, los que se alíen para ver allí donde hay otro, allí donde se inscribe la posibilidad de lo nuevo, nada más que las marañas de lo no resuelto en el mundo interno de los grandes?, ¿se podría pensar de otra manera que denominándolo trabajo psíquico, al trabajo del pensar, repensar, descubrir, redescubrir e insistir, sin dejarse llevar acríticamente por los modelos que se proponen estelares únicos, las nociones hegemónicas, las respuestas simples a lo que, no ignoramos, es complejo?

Desde esta perspectiva: ¿Qué tendrían que, además, saber los que se propongan formar a los educadores y los educadores? Importaría tener presente que a los que se los considera "maestros", se les atribuye algo más allá de los saberes que disponen. Algo que desborda o no coincide con tal o cual saber, ni con un saber en sí, sino con un saber que concierne a algo que nos concierne ${ }^{32}$, no estamos diciendo que corresponde a formas pragmáticas ni utilitaristas, sino que nos concierne en la medida que permite tramitar algo del orden de un enigma subjetivo, en campos objetivables designados social y culturalmente, y por ello mismo, sin referirse a nosotros, sin concernirnos "directamente", nos dice algo de nosotros, de nuestras historias. Como si se tratara de un saber construido para sernos dedicado, para ser compartido con nosotros y permitirnos, de ese modo, pensar y vivir (Frigerio, 2005).

En esos casos, no está en juego una verdad sobre su saber ni sobre la posición que ocupan en la escena objetiva en la que los designamos maestros. Lo que cuenta es la eficacia frente a nosotros mismos de esta atribución. Eficacia que se expresa en un darnos a pensar, invitarnos a explorar, animarnos a decir. Hay un maestro sólo cuando esta atribución ofrece la prueba de su eficacia simbólica.

A modo de síntesis, podría decirse que educar se conjuga en dos registros intrincados: el de la construcción de condiciones para el lazo social, y el que podría identificarse como encontrar un destino a una pulsión identitaria y ofrecer una ocasión (al modo de un objeto transicional) para la pulsión epistemofílica. Desde esta perspectiva afirmaremos que educar es un trabajo que necesita saberes y también exige (aunque esto pueda parecer contradictorio) saber ignorar los saberes a los que llamaremos saberes obturantes, entre los cuales el falso saber del prejuicio o el saber del "ya se sabe omitido" (sea este lo que ya se sabe y se rechaza o del que se reniega, renunciando a la idea de un aprendizaje que se interponga a perpetuar la reproducción), como el "ya se sabe obturante", que consiste en remplazar lo que no se sabe del futuro incierto por un pasado mal interpretado, son sus rostros más terribles y de efectos más devastadores. Por ello nos detendremos en lo que consideramos un tan curioso como necesario saber: el saber ignorar.

\footnotetext{
${ }^{32}$ La descripción que hace Baudelot de cómo Bourdieu hacía que todos se sintiesen concernidos es ejemplar en ese sentido.
} 


\section{El curioso saber necesario: el saber ignorar}

Distintas cuestiones vuelven imprescindible analizar los límites de las posiciones políticas y teóricas que están en juego en la compleja problemática de la formación de educadores. ¿Será que en materia de formación docente, la pregunta deba incluir no sólo lo que se debe saber $-\mathrm{y}$ es obvio que nunca se sabrá todo-, sino lo que se debe ignorar, en el sentido de des-oír; de-construir, des-naturalizar?

El lector comprenderá que en lo que estamos planteando no estamos haciendo el elogio de una ignorancia que sea equivalente a un no saber. Sino al trabajo de dejar de lado, desnaturalizar, desoír, aquello de lo que al no ser pensado se traduce en pre-juicio que influye, condiciona, hace pantalla, impide el encuentro con el otro (con lo enigmático del otro) y con el saber (con lo enigmático de lo por-conocer).

Sostendremos aquí que, si formar docentes está estrechamente relacionado con los saberes y su transmisión ${ }^{33}$, también lo está con los des-aprendizajes, y hasta con lo que debe ser ignorado en el sentido de des-naturalizado (entiéndase aquello que habiéndose vuelto "natural" debe recuperar su carácter de construcción política, social y pedagógica). Si se expresa y se espera como "identificación", será necesario considerar que habrá y serán necesarias "des-identificaciones".

Considerando, a modo de un ejercicio político e intelectual, que sin estos componentes toda intervención, aún cuando lleve el nombre de pedagógica, nunca se inscribirá en lo que la sociología de la educación bautizara como una "pedagogía anti hándicap" (une pédagogie contre handicap ${ }^{34}$ ). Una pedagogía antidéficit, cuyo principio activo es mantener una oferta que considere al que aprende renunciando a definirlo desde sus carencias. Recientemente Pierre Legendre (2009), denunciaba: "la pedagogía de la debacle", como aquella que se hace eco de las fracturas sociales, mimetizándose con ellas y reproduciéndolas.

${ }^{33}$ Pedimos a los lectores no rechazar el verbo transmitir, ni interpretarlo de manera mecánica. Para reconsiderar la noción, nos remitimos a "La transmisión en questions", de Nancy, France, 2006. En Frigerio, G., y Diker, G. (Comp.). La transmisión. (2004).

${ }^{34}$ Remitimos a la sociología de Bourdieu y Passeron, y sugerimos la lectura del libro elaborado bajo la dirección de Bouveresse, J., y Roche, D. (2004). La liberté par la connaissance. Pierre Bourdieu (1939-2002), publicado por el Collége de France y la Ed. O. Jacob en Francia.

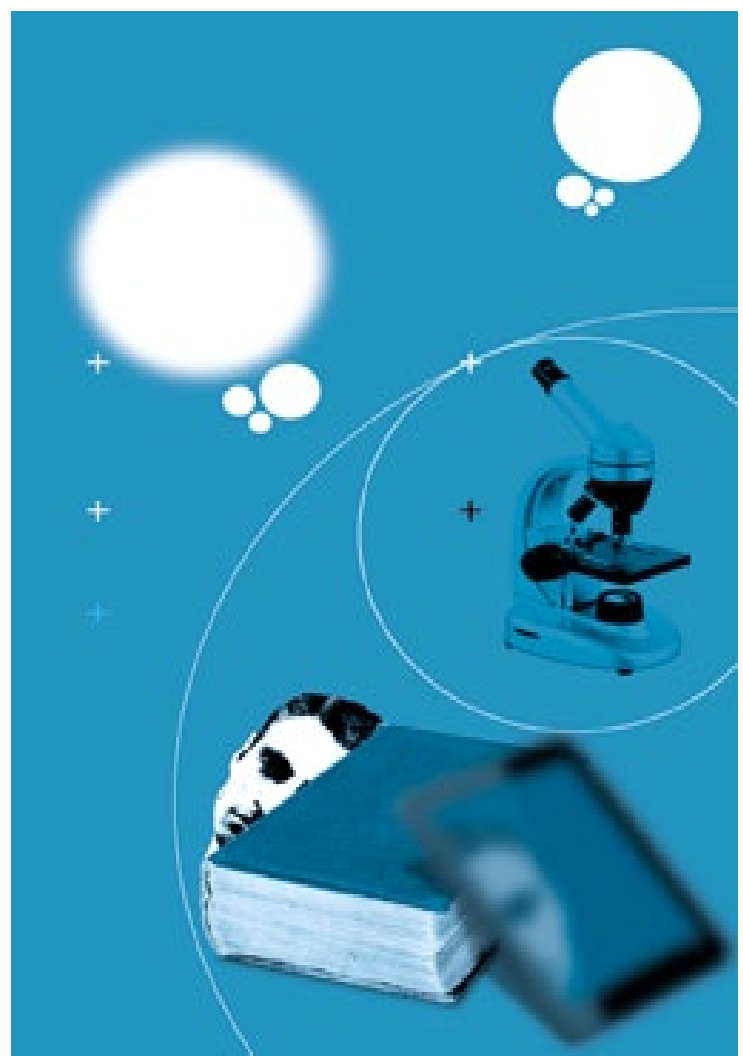

De tomar esta perspectiva (aunque fuera momentáneamente), podríamos formular quizás otras preguntas y otras respuestas tentativas. Nos interesa en particular la siguiente pregunta: ¿Quienes pueden aprender? Frente a la cual, entendemos que la mejor respuesta del educador debería ser: todos pueden aprender. Si su respuesta fuera otra, su capacidad de intervenir pedagógicamente estaría limitada, porque estaría condicionada a la naturalización de la que ha sido objeto la desigualdad.

En consecuencia, saber que todos pueden aprender implicaría, quizás, des-aprender las concepciones que adjudican a algunos sujetos la imposibilidad de establecer relaciones de saber. Conlleva ignorar (dejar de lado) y deconstruir (desnaturalizar) lo que se ofrece como interpretación natural de las dificultades de aprendizaje. Será necesario des-identificar a los sujetos de la afirmación que los tilda como los que "no podrán acceder a saber". 
66 Lo que decimos es que aún así, cada niño tiene que tener la oportunidad de que su futuro no esté completa y exclusivamente determinado por su origen.

Todos pueden aprender ${ }^{35}$ es lo que siempre han dicho y dirán una y otra vez en distintas lenguas todos los "maestros emancipadores" 36 en distintos continentes y en todas las épocas. Ellos renuevan la afirmación formulada por J. Jacotot ${ }^{37}$, poniendo en acto prácticas que discuten las profecías de fracaso ${ }^{38}$. Se sabe (aunque parece que no quiere saberse tanto), que las profecías producen efectos e insisten en reproducirse, en una reiteración que está a cargo de políticas y sujetos que terminan manteniendo un orden social encargado de trazar la línea divisoria entre "herederos"39 y desheredados.

¿Se trata entonces de saber ignorar las profecías? Obvio no estamos promoviendo una visión naif ni simplista que desconozca la existencia de circunstancias adversas que ponen en crisis la disponibilidad de aprender o inhiben el deseo de saber, simplemente afirmamos que saber que todos pueden aprender no es una consigna voluntarista, sino una realidad que exige la voluntad de deconstrucción de los aparatos etiquetadores a los que nos han habituado las economías de la desigualdad, las políticas des subjetivantes, las voluntades reproductivistas, los defensores de un mundo clivado, los amantes de las prebendas y los privilegios, los que hacen su capital cultural privatizando las herencias colectivas.

${ }^{35}$ Afirmación que se sostiene cuando se hacen propias las afirmaciones del pedagogo contemporáneo de Kant, Joseph Jacotot, y del filósofo Jacques Rancière, nuestro contemporáneo.

${ }^{36}$ Para Jacotot los maestros podían identificarse como emancipadores o, caso contrario, como embrutecedores.

${ }^{37}$ Jacotot fue recientemente re-significado por Jacques Rancière, a través de su libro El maestro ignorante. Cinco lecciones de emancipación intelectual Ed. Laertes, Madrid, 2004.

${ }^{38}$ Para ampliar, se recomienda la lectura de Frigerio, G. (2004). "La no inexorable desigualdad". En Álvarez Guerrero, O. (Ed.). Ciudadanos. Revista de Crítica Política y Propuesta, Año 4. № 7/8. Buenos Aires.

${ }^{39}$ Los lectores reconocerán la noción que profundizó Bourdieu.
Para deconstruir las máquinas de etiquetar y excluir hacen falta: los conceptos de la filosofía, los aportes del psicoanálisis, nociones y miradas que se animan a explorar la educación renunciando a conquistarla o a volverse hegemónicas; las apuestas a una pedagogía que se sostenga sobre lo que hay, sobre lo que se tiene, sobre lo que está (no sobre las carencias ni los déficits), sobre el hecho de que los maestros pueden producir saber pedagógico.

Esto significa desaprender, o aprender a ignorar, las dudosas enseñanzas que fueron creando la división entre expertos y enseñantes, entre intelectuales y ejecutores, entre pensantes y aplicadores. Enseñanzas invisibilizadas en su institucionalización, que se han sedimentado en la memoria de la profesión, perdiendo su historicidad, que para ser develada requiere de los saberes de la historia.

También significa preguntarse: ¿Como ocurrió que los productores primeros de saber pedagógico quedaron fuera del campo de la producción de saberes y pasaron a ocupar posiciones subalternas? Para responder será necesario recurrir a la sociología, a la historia, a la filosofía política y, con sus instrumentos, desnaturalizar lo que se volvió parte de un imaginario instalado y que obstaculiza, si no impide, toda transformación auténtica y profunda. Habrá que saber ignorar la barrera ficticia y discutir las posiciones ocupadas. Ignorar las barreras es algo que no puede hacerse ignorado los saberes, incluso (o sobre todo) aquellos que estuvieron al servicio de la construcción de las mismas.

Debería agregarse que será en simultáneo, en tanto ciudadanos, que los maestros y los que no lo son, se propongan participar del arduo trabajo político (de pedagogía pública y no de pedagogía escolar), para que las necesidades básicas insatisfechas dejen de serlo, lo que sólo se obtendría insistiendo una y otra vez para que sean las políticas de reconocimiento y distribución las que caractericen a los nuevos tiempos. Para un educador sería un apoyo saber que "todos pueden aprender", pues supone la puesta a disponibilidad de una confianza ${ }^{40}$ en los sujetos, en su "deseo de saber"

\footnotetext{
${ }^{40}$ Acerca de la confianza, y en particular la confianza en las relaciones pedagógicas, recomendamos la lectura de los trabajos de Laurence Cornu (1999). "La confianza en las relaciones pedagógicas". En Frigerio, G., Poggi M., y Korinfeld, D. (Comp.). Construyendo un saber sobre el interior de la escuela. Bs. As.: Centro de Estudios Multidisciplinarios y Ediciones Novedades Educativas.
} 
y en las relaciones pedagógicas. Puesta a disposición sin la cual la oferta de objetos de conocimiento ${ }^{41}$ no encontrará eco.

Un educador debería saber que a la pregunta: ¿Cual es la convicción ${ }^{42}$ que hace posible que todos puedan aprender?, hay disponible una respuesta muy discutida por cierto (por los que han hecho del concepto de inteligencia, midiéndola o segmentándola, el argumento para la discriminación), pero contundente (en todo caso lo suficientemente con-movedora como para que nos animemos a no descartarla inmediatamente sin someterla a una reflexión): El principio de que las inteligencias son iguales ${ }^{43}$; es decir, dirán sin dudarlo Jacotot y Rancière provocando nuestra adhesión a ese principio estructurante de la enseñanza, una confianza en que todo hombre puede comprender la palabra de otro hombre, punto de partida que implica que todo educador sale a la búsqueda de confirmar el principio, organiza sus actividades para comprobarlo y, al hacerlo, lo vuelve real y concreto.

Es este principio el que desafía a los contextos adversos, denuncia la hipocresía de adjudicar, para unos, las "condiciones de educabilidad" y para otros, la ausencia de las mismas y vuelve posible que las diferencias no se constituyan en la sede ni en la excusa para las desigualdades.

La afirmación "todos pueden aprender" no conoce límites provenientes de la asignación de roles. Chicos y grandes, alumnos y educadores, todos pueden apren-

${ }^{41}$ Tengamos en cuenta que entendemos que una institución educativa, una escuela, es la organización que permitiría sostener una oferta de conocimientos, volviendo disponible para todos el capital cultural que debe ser compartido, haciendo accesible a todos la herencia común.

${ }^{42}$ La convicción no es objetiva, pero tampoco arbitraria ni caprichosa, está, para la teoría freudiana, asociada a un testigo (Zeug). Freud así lo deja entrever en su trabajo de 1905: Fragmentos del análisis de un caso de histérica, y sin embargo, será en De la historia de una neurosis infantil (1918), donde señala que lo único que se espera de una publicación es aportar algo nuevo a aquellos que por su propia experiencia "ya se han procurado convencimientos".

${ }^{43}$ Remitimos al texto de Rancière; Agregamos en Anexo un articulo que asume la argumentación a favor de este principio: "La Educaco \& Sociedade" V. 24, de Abril de 2003, Revista de Ciencia da Educacao, y además sugerimos el dossier: Lecoes de um ignorante. Ressonancias. aparecido con ocasión de la traducción del libro de Rancière al portugués. der. Sin embargo, los roles diferenciados conllevaban una asimetría que el educador no debería desconocer, asimetría que le impide desentenderse de la responsabilidad y de la autoridad ${ }^{44}$ de educar.

A su vez, el principio de la igualdad de las inteligencias no anula la búsqueda de los modos pedagógicos por los cuales se "forzará a una capacidad que se ignora a reconocerse" ${ }^{45}$, ni invalida la puesta a disposición de los objetos culturales que, a modo de objetos transicionales, sostendrán una oferta aun cuando no exista demanda, con el convencimiento de que es la oferta la que puede suscitarla dando lugar a relaciones de saber. Disculpe el lector si insistimos en abundar, o dar más precisiones, acerca de los efectos del terrible "ya se sabe" que hace falta ignorar. (No queremos dejar de señalar que hay un ya es sabido que hace falta reconsiderar y reconocer, como es el de la experiencia).

Podría decirse que, la mayor dificultad de aprendizaje no se encuentra en los chicos, como suele creerse, sino en los adultos atrapados en prejuicios, saberes $o b$ turantes y en una dificultad para asumir una adultez responsable frente a las nuevas generaciones. La dificultad de aprendizaje habla más de los educadores que de la población escolar.

En los territorios concretos, el fracaso escolar en sus múltiples y diferentes formas, encuentra sus argumentos en saberes obturantes. Entendemos por tales a los que nos ofrecen las construcciones teóricas que naturalizan las variables en juego, que hacen que pese sobre el sujeto singular o las constelaciones familiares, o la pertenencia a ciertos sectores sociales, la responsabilidad, cuando no la culpa, de un fracaso. Procedimiento que omite incluir lo que realmente fracasa (la institución educativa).

Por supuesto, no estamos diciendo que los aspectos mencionados no intervienen en la relación que los chicos establecen con la educación institucionalizada en formatos escolares, estamos señalando que la adjudicación a priori de representaciones clasificatorias descalificantes, impide que los educadores se encuentren con los chicos reales, sin adjudicarles de antemano una

${ }^{44}$ Respecto a la autoridad en las relaciones pedagógicas recomendamos las investigaciones dirigidas por Gabriela Diker (2005). ¿Es posible una educación sin autoridad? Relaciones de autoridad en la escolarización de adolescentes y jóvenes. UNGS /CEM/ UNESCO - OREALC.

${ }^{45}$ De este modo se expresaría Rancière reanudando con Jacotot. 
naturaleza, antes que para mantener, acerca del otro, abierta la respuesta sobre de lo que es y será.

Anticipar cualquier respuesta significaría "encarnar un saber" que se volvería condenatorio tanto en lo que concierne a los herederos como a los desheredados, ambos colocados en el difícil y tramposo lugar de obedecer a mandatos (los primeros colocados en la situación de confirmar y cumplir los proyectos familiares y de clase a la letra, los segundos colocados en su mayoría en la situación de cumplir, igualmente a la letra, con la profecía de fracaso que les ha sido pre-asignada socialmente).

Suprimir este enigma del otro por ciertos saberes condenatorios, restarle a las infancias la extranjería necesaria para que desplieguen en las relaciones pedagógicas lo insospechado, lo posible y lo impensado, es una operación reiterada que se incrementa en la misma medida en que las dificultades existenciales se condensan en sectores cada vez más mayoritarios de la población. ¿Se tratará entonces en la formación docente de desoír los saberes condenatorios?, ¿¿, mejor aún, de de-construirlos para comprender al servicio de qué exclusiones trabajan?, ¿por qué no imaginar que de lo que se trataría es de saber ignorar los saberes obturantes?

A modo de ejemplo, mencionemos que un saber obturante ha sido, entre otros, lo que Frigerio (2009), llama el discurso que circula y ofrecen las políticas de la pobreza. La opción, por cierto tentadora, de formar educadores para que se desempeñen en contextos de "vulnerabilidad", en condiciones adversas, con poblaciones "marginales", carenciadas, es fuertemente discutida por aquellos que, como Serra, S. (2006), entienden que al hacerlo se desliza una mimetización con "el otro pobre" (el "otro pobre”, por pobre, sólo necesitaría saberes elementales y rústicos de supervivencia) ${ }^{46}$, que

\footnotetext{
${ }^{46}$ Una amplia bibliografía puede hallarse acerca de las denuncias acerca de cómo se reproduce la producción de desigualdades, aún bajo nociones aparentemente superadoras (la diferencia, la alteridad, etc.). En todo caso, señalamos que un ejemplo de esa elaboración, de ese efecto de saber, puede leerse en la trascripción de la mesa redonda que coordinara Baudelot, en su propia ponencia bajo el título “Ce qu'il m’a appris", que aparece en La liberté par la connaissance Pierre Bourdieu (1930-2003), de Jacob, O. (Ed.) (2004), 334, 335, 336.
}

construye una oferta empobrecida y por tanto discriminatoria ${ }^{47}$

¿Será cuestión entonces, en la formación de un educador, de enseñarle a de-construir para que pueda des-aprender un cerco cognitivo, para que lo ignore?, ¿para que sepa que puede tener otros saberes?, ¿para que sepa que puede educar?, ¿significa esto que, trabajar en contextos donde se condensan situaciones existenciales extremas ${ }^{48}$, no requiera un particular trabajo de acompañamiento? No nos precipitaríamos a esta opción, pero nos importa destacar que tanto en ese acompañamiento, como en la formación de un educador, trabajar con otros, y en particular con niños, exigiría para todo adulto, contrariamente a lo que se afirma, no sólo, o hasta quizás menos, un saber sobre el otro, que un saber sobre sí $^{49}$.

\section{El saber que no se podría ignorar: el saber sobre sí}

Estamos habituados a hacer repertorios entre los saberes disciplinarios e incluir saberes sobre los niños. Estamos menos habituados a considerar que un saber que no puede omitirse es el saber de los grandes sobre sí.

¿Un saber sobre sí?, ¿qué debemos saber los educadores sobre nosotros mismos? Algo que es muy sencillo de decir y que requiere de un trabajo sostenido y sin contemplaciones acerca de comprender qué se moviliza en el mundo interno cuando estamos frente a los alumnos, qué razones -o sin razones- nos llevan a adherir a políticas empobrecidas, por qué la mimetización al malestar, la tendencia a la victimización, y preguntas como: ¿Qué beneficio secundario se obtiene al formar parte de la reproducción de las desigualdades?, ¿que nos liga a lo que queremos dar a saber?, ¿qué ocurre cuando los propios lazos a las lenguas extranjeras están debilitados o interrumpidos?, ¿qué nos lleva a aceptar de manera resignada la rutinización de las prácticas?, ¿qué nos impulsa a un complejo, incómodo,

${ }^{47}$ El efecto de clasificar ha sido denunciado por la sociología de Bourdieu, por la filosofía de Rancière, por la pedagogía de Jacotot, para citar algunos referentes que el lector puede rastrear.

${ }^{48}$ Para ampliar el término se recomienda ver Frigerio, G., y Diker, G. (Coord.). (2006). Infancias y adolescencias. Teorías y experiencias en el borde. La educación discute la noción de destino. Noveduc / CEM, Colección Ensayos y Experiencias N 50, Buenos Aires.

${ }^{49} \mathrm{Al}$ respecto, es posible ampliar el término con la lectura de Frigerio, G. (2008). La división de las infancias. Bs. As: Estante editorial. 
pero confortable conformismo?, ¿qué de nuestro propio mundo interno se conmueve frente a los pequeños, qué de lo no resuelto en él, se reactualiza -a veces a pesar nuestro- frente a ciertos alumnos en ciertas circunstancias?

Quisiéramos que quedara explicito que no estamos sugiriendo ningún tipo de "terapia” obligatoria, que no coincidimos con las intervenciones institucionales que se sostienen en el desnudar la vida del otro o en solicitar "decirlo todo". Que no se trata para nosotros de apoyar ninguna “aplicación” del psicoanálisis (ni de ninguna otra construcción) "sobre" la pedagogía. Sino de explorar la pedagogía con conceptos que pueden sobresaltar y poner de manifiesto, no lo que cada uno siente y piensa, sino lo no pensado en ese campo.

¿Es posible integrar una formación sobre sí, que no se transforme en impuestas y falsas terapias salvajes? Estamos convencidos de que el recorrido por ciertas disciplinas, el trabajar con conceptos que exploran las relaciones pedagógicas, produce una elaboración, un efecto de saber que, haciendo la economía de las formas brutales, de la puesta en evidencia de problemáticas singulares, intimas y personales, permite llevar adelante el trabajo sin producir efectos que se pretenden evitar, sin recurrir a explicaciones "científicas" que antes que posibilitar, cierran, sin desvestirse de los atributos de "prestador de identidad"50 necesarios para el mantenimiento de la "feliz oferta de filiaciones múltiples" 51 , que hace de lo que esperamos que la educación sea, habilitación de la oportunidad ${ }^{52}$.

Un antídoto posible al "ya se sabe”, podría entenderse como la confianza, ¿es posible formar en "la confianza en que todos pueden aprender"? Diremos que propiciar esto sólo podría ocurrir:

a. Poniendo en discusión (des-aprendiendo) las teorías psicológicas y sociológicas que indican lo contrario, y para eso hace falta incorporar cierto modo de pensar la psicología y la sociología a la forma-

${ }^{50}$ Para ampliar el término se recomienda la lectura de Kammerer, P. (2000). Adolescents dans la violence. Gallimard. France.

${ }^{51}$ Pontalis, J-B. el psicoanalista; Derrida J y Badiou, A, los filósofos, coinciden en la importancia del más de uno de la oferta filiatoria.

${ }^{52}$ Ver al respecto, a Frigerio, G., y Diker, G. (Coord.). Una ética en el trabajo con niños y adolescentes: La habilitación de la oportunidad. Noveduc /CEM, Colección Ensayos y Experiencias N. 52. Buenos Aires, 2004. ción, es decir, sus saberes más inconfortables, los más urticantes.

b. Desnaturalizando los efectos de la forma escolar, para eso hace falta volver a incorporar a la formación de educadores los modos de pensar, es decir, los saberes que ofrecen la historia y la pedagogía.

c. Deconstruyendo la idea misma de naturaleza infantil y su funcionamiento normativo, para eso hace falta introducir ciertos análisis críticos a la psicología educacional, nos referimos a los saberes que conmocionan y que estallan los saberes que fracturan a las infancias.

d. Revisitando y re-interrogando algunos conceptos, para lo cual es necesario el pensamiento filosófico, es decir, ese particular saber sobre sí y sobre los otros que intenta trabajar los enigmas propios a lo humano.

Como se puede observar, des-aprender no significa renunciar a los saberes ni dejar de considerar cuáles, dónde, son pertinentes en la formación docente. A la vez que se mantiene la inquietud sobre qué habría que ignorar, des-aprender, durante la formación de los educadores; cuya respuesta sería, en principio, todo aquello que se considera "natural" o "fuera de cuestión" (en el sentido de incuestionable). Finalmente, queremos referirnos a otro saber tan "alterado" cómo "alterante".

\section{Saber sobre lo que cuenta (sin ninguna certeza confortable) y no es del orden de un régimen contable}

El saber sobre sí es el que permite a cada educador responder para sí, a la pregunta planteada por la intensa actividad hermenéutica a la que se libran los niños. Algunos investigadores, como Fostier (2000), afirman que frente a cada adulto que despliega una actividad profesional, aquellos a los cuales está destinada su acción cotidiana, y tanto más si son pequeños, se libran a una "intensa actividad hermenéutica".

¿Qué significa esto? Imaginemos un niño frente a un adulto con el que comparte durante muchos días de su infancia y adolescencia, una importante cantidad de tiempo diario y un espacio organizacional, en el marco de una práctica (la educativa) que carga con sentidos sociales, familiares y singulares. El niño (el adolescente) quiere saber: ¿Por qué el otro está ahí?, ¿por qué decidió ejercer ese oficio?, ¿qué lo impulsa a ir a trabajar todos los días?, ¿por qué hace lo que hace?, ¿qué lo motiva?, ¿qué razones lo impulsan?, ¿qué lo sostiene en el día a día escolar?, ¿por qué enseña lo que enseña? 
Pero por sobre todo, esas preguntas, que lógicamente no necesariamente tienen ese registro al momento de ser pensadas en el mundo interno de un niño, expresan una curiosidad interior relativa al sentido que su propia presencia como niño/alumno tiene para el adulto educador. Se pregunta el niño: ¿Qué significo para él?, ¿qué papel juego en su insistencia en ejercer ese oficio?, ¿existo, cuento, que significo para el otro?

Todas esas preguntas, y otras equivalentes, cuyo registro más elaborado podría traducirse en inquietudes tales como: ¿Qué de vital se moviliza para el educador?, ¿qué lo sostiene en su aula, con su clase?, ¿qué tipo de relación lo enlaza con lo que enseña?, ¿por qué quiere que yo aprenda?, ¿por qué viene a la escuela todos los días?, ¿es la enseñanza su gagne pain?, ¿podría trabajar de educador o de otra cosa con tal de asegurar su subsistencia?, o bien, ¿además del contrato laboral que está en juego, otros factores intervienen en su elección? El conjunto de respuestas a estas preguntas, sea como sea que cada pequeño se las formule en su imaginario, en sus representaciones simbólicas, tendrá efectos concretos en la textura de las relaciones que se tejan entre alumnos, educadores y conocimientos.

Sin duda, educar no es "cualquier trabajo”, y por ello mismo no dará igual si un niño se contesta a sí mismo (contestación que obviamente depende de cómo a su vez el adulto significa lo que hace), que el otro "está ahí sólo porque le pagan”. Respuesta que puede darse aún sin desconocer que se trata de un oficio que requiere de un contrato laboral (el que, por otra parte, no debería ser cualquier contrato), que imaginar, suponer, constatar que cada educador además de por qué es un trabajo inscripto en la lógica de los intercambios salariales, está ahí también, además, en parte, porque el pequeño le importa, que es un modo de entender que está ahí porque algo, un plus, otra cosa cuenta en su cuenta para él.

Anticipándonos a posibles reacciones frente a lo señalado, queremos advertir que esto no significa, desde la perspectiva que ponemos a discutir en este ensayo, desconocer que se trata en lo "objetivable" de un trabajo, que las reglas de juego contractuales deben ser atendidas, que no es indiferente el modo en que tal trabajo sea reconocido salarialmente por el Estado, que sostiene tanto la "educación obligatoria" como el "derecho a la educación” para todos los niños.

A lo que apuntamos es a compartir, desde nuestra propia relectura, las propuestas de los que han investigado los oficios que se despliegan, en el registro de la

\section{$\int($ El saber sobre sí es el que permite a cada educador responder para sí, a la pregunta planteada por la intensa actividad hermenéutica a la que se libran los niños.

interpretación, cabalgando en una insoluble ambigüedad entre "la lógica del contrato salarial" y la lógica del "don" "53, y que formulan la hipótesis de que lo más fructífero es que el adulto que lleva adelante la tarea pueda sostener, en el otro, una duda imposible de zanjar. O bien, dicho de otro modo, que hagan lo posible para que el pequeño, el alumno, el niño, construya a modo de respuesta a las preguntas, una afirmación no excluyente: el adulto que está ahí hace un trabajo, lo hace porque es su trabajo y, a la vez, ese adulto hace lo que hace "también" porque el otro (el niño, el pequeño, el alumno) le importa, y entonces, pone en juego un excedente, un plus, que entra sólo en una contabilidad subjetiva en la que no hay ganancia sino "don". Gratuidad del plus que permite a un pequeño, a un niño, a un alumno, confiar en que "él cuenta para el grande”.

Cabe agregar que, en ninguna relación se trata de "contar para el otro" de cualquier manera (por ejemplo la caridad y la beneficencia dice que el otro cuenta, pero el lugar que le asignan está lejos de ser un lugar con potencial emancipador), contar para el otro es una expresión que implica la actividad de re-conocer ${ }^{54}$.

\footnotetext{
${ }^{53}$ Al respecto, sugerimos volver a retomar la producción de Marcel Mauss, en especial el "Ensayo sobre el don" en Sociología y antropología (1925) (varias ediciones en distintas editoriales; se recomienda contrastar esa interpretación del don con la que elabora el filósofo Jacques Derrida, en especial, la que expone en Dar el tiempo o la falsa moneda, relacionarla con el trabajo de Jacques Ranciere El maestro ignorante o cinco lecciones de emancipación intelectual que a su vez remite a la producción de Jacques Jacotot. Por último es posible consultar en La société vue du don manuel de sociologie anti utilitariste appliquée, obra dirigida por Philippe Chanial, 2008.

54 Sugerimos además de volver a leer la producción de Ricoeur, consultar a V. de Gaulejac y su libro Las fuentes de la vergüenza, 2008.
} 


\section{Despedida}

Pensar no es una actividad cualesquiera nos recuerda Enriquez (2006), cuando afirma que pensar es un modo subversivo de aprehender el mundo, caracterizado por hacer(se) las preguntas más inauditas, incluso aquellas cuya respuesta ignoramos completamente, y animarse a asociaciones de ideas que no parecían destinadas a relacionarse.

Intentar explorar respuestas posibles y políticamente y pedagógicamente necesarias para la formación de educadores, necesariamente modifica las preguntas acerca de lo que está en juego. "Pensar" sobre las preguntas es algo que no se puede llevar a cabo confortablemente, para que preguntarse tenga sentido, las cuestiones deben ser inquietantes ${ }^{55}$, no tener a mano respuestas certeras, renunciar a los cercos cognitivos que de antemano ofrecen la (cuestionable) tranquilidad de respuestas ya hechas; descreer del "ya se sabe", para encontrar el sentido de una exploración.

Retomando algunos de los hilos sueltos: sabemos algo acerca de lo que se cree que "falta". Parece sencillo admitir que: los saberes de los que disponemos son insuficientes y otros ni siquiera están considerados como necesarios. Se vuelve evidente que los saberes encapsulados en las disciplinas, los que no se animan a atravesar sus fronteras, abundan pero parecen ya no ser fértiles.

Escuchando a los educadores en ejercicio se oye la denuncia de que los saberes que se ofrecen en la formación docente parecen no conformar ni alcanzar, pues afirman que "no saben como" sostener una cotidianeidad conmovida por necesidades básicas insatisfechas y reconfiguraciones identitarias desconcertantes.

Podría decirse que en parte esto sucede porque lo nuevo, las nuevas generaciones, ya no se identifican con lo pre-sabido; en parte porque lo nuevo adquiere formas que no coinciden con las normalizaciones previas, resistiendo a dejarse encerrar en lo ya sabido, o porque la actualidad desconcierta con sus instalaciones y afecta las texturas ${ }^{56}$ de la experiencia escolar contemporánea.

${ }^{55}$ Para ampliar el término, recomendamos la lectura de Frigerio, G. (2007). "Inventarios para ampliar lo pensable". En Baquero, Diker, y Frigerio. Las formas de lo escolar. Bs. As: Estante editorial.

${ }^{56}$ Esta textura también afecta a los docentes en ejercicio, que suelen señalar que "no fueron" / "no fuimos formados para...".
A la vez, la ausencia notoria de re-conocimiento (a los educadores, a los educandos, a los sujetos en general) que han logrado imponer las llamadas políticas des-subjetivantes, empieza a verse en sus efectos y dejando al desnudo sus necesidades. Se halla allí a la vez un argumento para ocuparse, y una preocupación que podría expresarse de este modo: toda política del conocimiento exige una política del re-conocimiento.

No deberíamos omitir, en la descripción de lo complejo, que un saber que no circula lo suficiente ${ }^{57}$ : es el saber pedagógico producido por los propios educadores. Docentes en formación necesitan de saberes pedagógicos producidos por educadores, y requieren de los instrumentos teóricos para producir sobre sus prácticas sus propios saberes, superando la dicotomía ficticia entre teorías y prácticas.

Un saber que intente aprehender algo, a propósito de cómo juega en la tarea de la transmisión la relación del educador con su saber supuestamente sabido (el que concierne a los cuerpos de saberes objetivables) y con su saber no-sabido (el que refiere al mundo interno de cada sujeto, sus posicionamientos subjetivos, sus fantasmas inconscientes y difícilmente objetivables), no será un saber "totalmente" nuevo, pero las exploraciones que sugieren y las que se intuyen son más complejas, las hipótesis ofrecen más matices y felizmente no lograrán dar un repertorio de todas las variantes.

Otras veces hemos escrito a modo de cierre, podríamos escribir nuevamente la misma frase, sin embargo la ocasión requiere de una "despedida". Obviamente no se trata de una expresión que indique que nunca más nos encontraremos (los que participamos del XIV y último seminario del CEM y los eventuales lectores de este libro). Otras instancias, otras páginas, nos permitirán reanudar los diálogos que mantenemos a viva voz y aquellos que sostenemos con nuestros interlocutores externos. Sin embargo, la decisión de cerrar el CEM y de concluir la producción del estante editorial, decisión tomada con serenidad y alegría, que es entre "los amigos del CEM" ocasión de festejo (como lo fue-

\footnotetext{
57 Estamos trabajando sobre tendencias, no desconocemos las iniciativas de grupos y agrupaciones que llevan a cabo un trabajo entre pares para producir saber pedagógico. En este sentido, hay experiencias de distintas escalas en diferentes países de América Latina.
} 


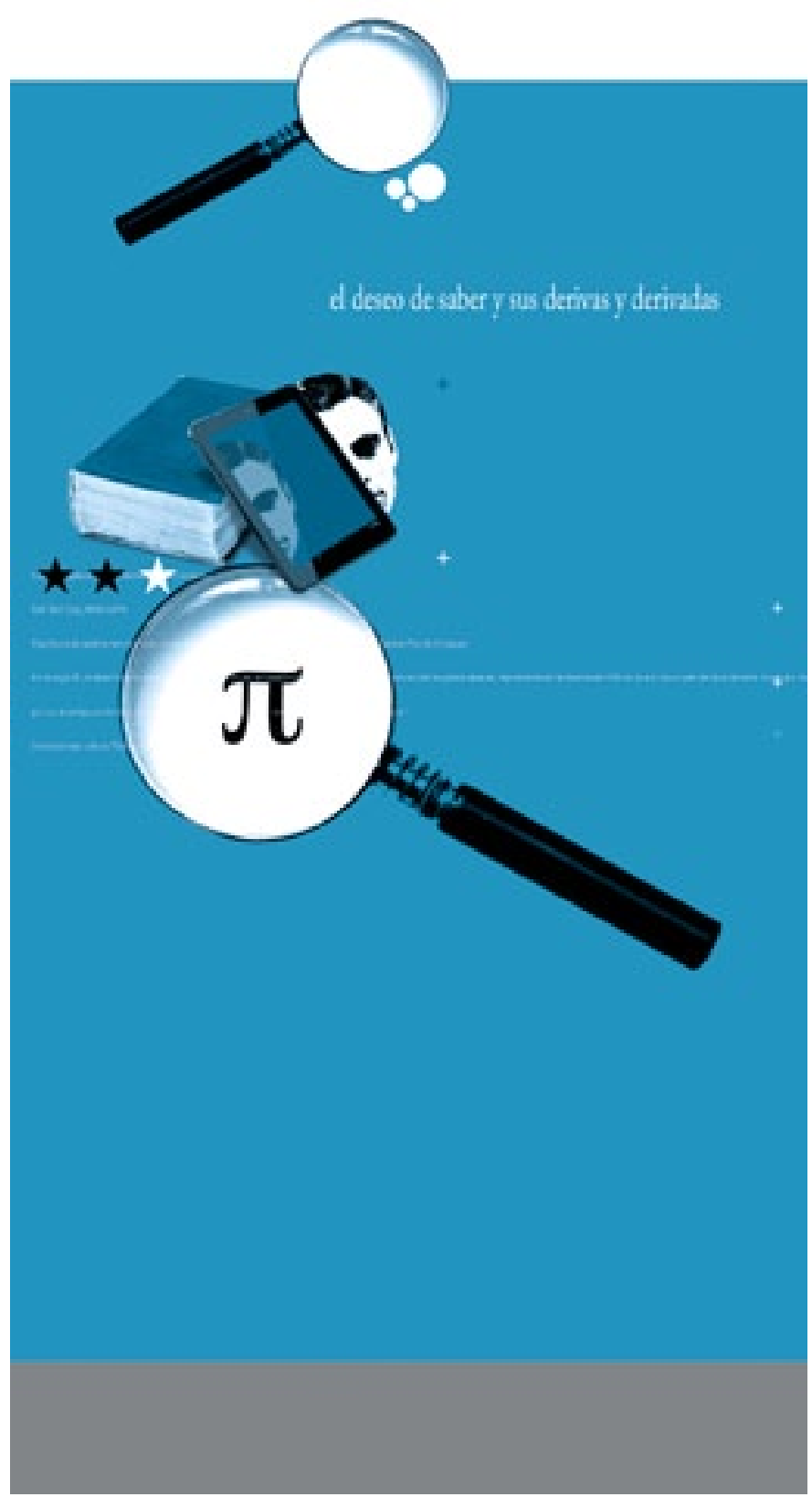

ra el de las creaciones y producciones de los últimos 15 años), justifica plenamente que nos despidamos.

No se trata aquí de dar trámite a lo que aquí no lo tiene, simplemente se busca dar a la cuestión del saber una vuelta más:

Es sobre la despedida, sobre los puntos de no retorno, donde la curiosidad se funda para el sujeto, es sobre el territorio jamás perdido de lo materno, donde el querer saber acerca de lo olvidado da lugar al querer saber sobre lo aún no conocido.

Es sobre el trabajo de duelo anticipado que impone el saberse mortal, que se funda la producción de un saber que desafía lo efímero del presente viviente.

Es sobre el trabajo de duelo que imponen las despedidas imperfectas (diría Michel Gribinski), pero no por ello reversibles, que el sujeto reordena sus saberes sobre sí, sobre los otros, sobre la vida, sobre la muerte, sobre el mundo y el tiempo del que es parte.

Es sobre el trabajo del suelo que impone todo despertar, que los saberes se vislumbran en su maravillosa incompletud, dando a ver, dejando ver, a la vez que mantienen los puntos ciegos de lo inatrapable, ese "ombligo del sueño" que Guy Rosolato nos mostró para hacernos saber la permanencia de lo insondable, el punto de no acceso, el callejón que no tiene salida pero que sin embargo no deja de ofrecernos más de un recorrido.

A ver... escribíamos al comienzo de este ensayo... el final... al final... hay saberes acerca de los que no sabremos sino allí, cuando y donde ya no podremos hacer nada con ellos, mientras, entre tanto, habrá que asomarse una y otra vez, obstinadamente como "los curiosos" de Conques, a lo que puede verse si queremos ver y saber. 


\section{Referencias}

Aulagnier, P. (2009). Les destins du plaisir. Francia : PUF.

Aulagnier, P., et al. (2009). La pensée interdite. Francia : PUF.

Beillerot, J., et al. (1989). Savoir et rapport au savoir. Paris: Ed. Universitaires, 165-202.

Beillerot, J., Blanchard L., y Mosconi, N. (1996). Pour une clinique du rapport au savoir. France: L’Harmattan.

Bigeault, J., y Agostini, D. (1996). Violence et savoir. L'intervention éducative et les " savoirs interdicteurs. Francia : L'Harmattan.

Blais, M. C., Gauchet, M., y Ottavi, D. (2008). Conditions de l'éducation. París: Stock.

Bonnet, G. (1996). La violence du voir. France : PUF.

Caillat, G. (2008). La fabrique de l'homme occidental (FILM) sur le texte de Legendre. Francia: Arte éd., Ideal Audience, CNC.

Camus, A(1953). El mito de Sísifo el hombre rebelde. Bs. As. : Losada.

Charlot, B. (1997). Le rapport au savoir. París: Antrophos, 94.

Chasseguet- Smirgel, J. (2004). Le corps comme miroir $d u$ monde. Francia : PUF.

Dorey, R. (1988). Le désir de savoir. Francia : Denoël.

Enriquez, E., Haroche, Cl., y Spurk, J. (2006). Désir de penser, peur de penser. Francia: Parangon.

Enthoven, R. (2009). La création. Francia: Perrin.

Fraisse, G., et al. (1991). L'exercice du savoir et la différence des sexes. Francia: L’harmattan.

Freud, S. (1996). La inquietante extranjeridad. Obras completas. V. XV. Francia: PUF.

Frigerio, G. (2005). Acerca de lo (in) enseñable. en Skliar, C., y Frigerio, G. (Comp.). Huellas de Derrida ensayos pedagógicos no solicitados por un maestro. Buenos Aires: Estante editorial.

Frigerio. G. (2008). Obstinaciones duraderas. En Frigerio, G., y Diker, G. (Comp.). Educar: posiciones acerca de lo común. Buenos Aires: Estante editorial.
Frigerio, G., y Diker, G. (2004). La transmisión. Bs. As: CEM/ NOVEDUC.

Frigerio, G., y Diker, G. (2009-Marzo). "Los proyectos de inclusión educativa y la problemática de su evaluación”. Eurosocial/CEM/ Informe final.

Fustier, P. (2000). Le lien d'accompagnement. París: Dunod.

Gomez Mango, E. (2009). Un muet dans la langue. Francia: Gallimard.

Green, A. (2007). Pourquoi les pulsions de destruction ou de mort? Francia: Panama.

Gribinski, M. (2009). Les scènes indésirables. Francia: Ed. del Olivier. Penser Rêver.

Harlé, I. (2010). La fabrique des savoirs scolaires. Francia: La dispute.

Jorion, P. (2009). Comment la vérité et la réalité furent inventées. Francia: Gallimard.

Kierkegaard, S. (1959). Estética y Ética. Bs. As.: Ed. Nova.

Korff-Sausse, S. (2001). D’Oedipe à Frankenstein. Figures du handicap. Francia: Desclée de Brouwer.

Lapanche, J. (1987). La sublimación. Problemáticas III. Argentina: Amorrortu

Legendre, P. (2009). La fabrique de l'homme occidental. Francia: Arte éditions.

Legendre, P. (2009). Vues éparses. Francia: Mille et une nuits.

Lévêque, J. (2005). Klimt, Kokoschka, Schiele un monde crépusculaire. Poche № 38. ACR Edition.

Mijolla-Mellor, S. (2002). Le besoin de savoir. Francia: Dunod.

Mijolla-Mellor, S. (2009). Le choix de la sublimation. Francia: PUF.

Miller, A. (2008). L'enfant sous la terreur. L'ignorance de l'adulte et son prix. Francia: Aubier.

Missenard, A., et al. (1999). Lo negativo y sus modalidades. Argentina: Amorrortu.

Curioseando (Saberes e Ignorancias).Graciela Frigerio 101 
Nancy, Jean-Luc. (2005). Hegel. La inquietud de lo negativo. Madrid: Arena libros.

Pasquet, Guy-Noel. (2009). L'oubli en éducation. Francia: L’Harmattan.

Rey, J. M. (2009). La haine de savoir. Penser/rêver, № 16. Francia: Ed. del'Olivier.

Revue Française de Psychanalyse. (1998-Octubre-Noviembre). La sublimation. T. LXII. Francia: PUF.

Revue Française de Psychanalyse. (2005-Diciembre). La sublimation. T. LXIX. Francia: PUF.

Ricoeur, P. (2004). Parcours de la reconnaissance. París: Stock.

Rosolato, G. (1978). La relation d'inconnu. Francia: PUF.

Rosolato, G., et al. (2009). L'ínconnu. Francia: PUF.

Roux, J. (2007). Inévitablement (après l'école). Francia: La fabrique.

Salomé, Lou-Andreas. (2001). Aprendiendo con Freud. Barcelona: Laertes.

Salvatore, Ricardo D. (Comp.). (2007). Los lugares del saber. Bs. As.: B. Viterbo editora.

Scheler, M. (1991). Sociología del saber. Argentina: Leviatan.

Serra, S. (2006). Pedagogía y metamorfosis. En Baquero, Diker, Frigerio, G. Las formas de lo escolar. Buenos Aires: Estante editorial.

Stern, Anne-Lise. (2004). Le savoir déporté. Francia: Seuil.

Terestchenko, M. (2009). Un si fragile vernis d’humanité. Francia: La découverte.

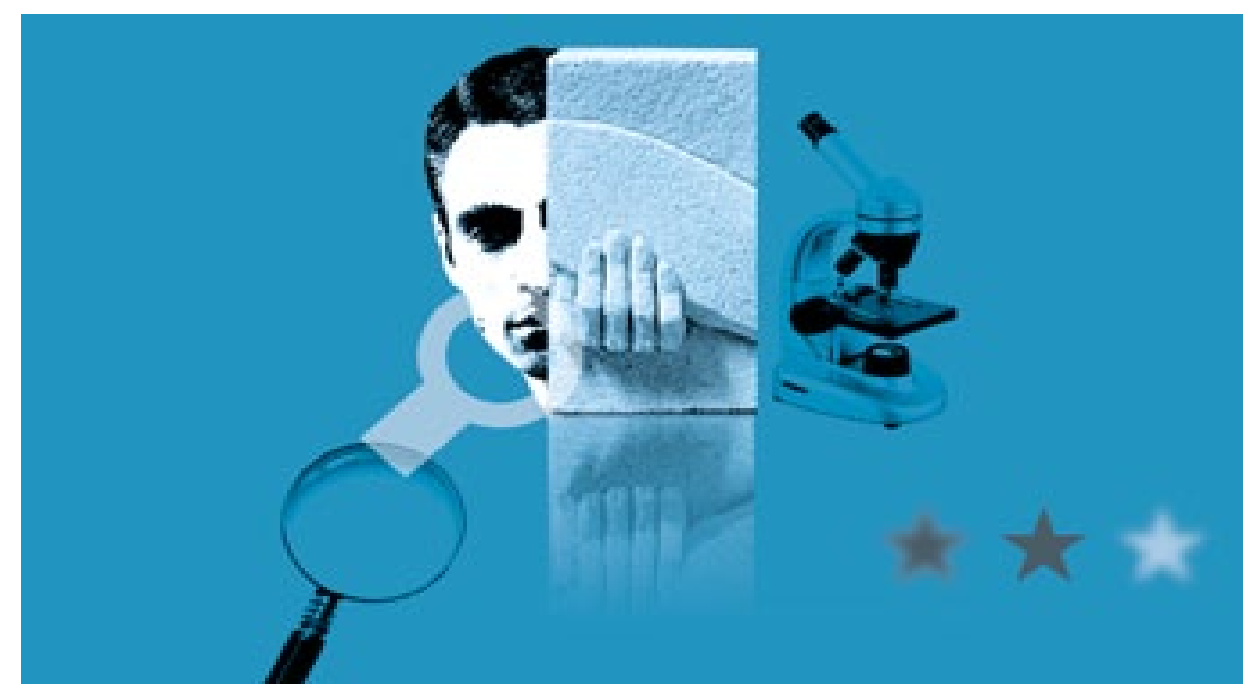

